\title{
From the Editar
}

Plummer Alston "Al" Jones, Jr., Editor

\section{Are Libraries Getting Their Fair Share of the Federal Budget?}

s I grow older and hopefully wiser, I have begun to question whether libraries are now or ever have been getting their fair share of the federal budget. Astounding as it may sound, the United States was 180 years old, just twenty years away from its Bicentennial, before the U.S. Congress passed the first law establishing federal funds for libraries in 1956.

The Library Services Act (LSA) passed that momentous year was targeted toward improving rural library service. In 1964, the LSA was broadened to the Library Services and Construction Act (LSCA), which provided funds for urban as well as rural public libraries and for library construction. Most recently in 1996, the LSCA was replaced with the Library Technology and Services Act (LSTA), which provides funds for enhancing the electronic capabilities of public, school, and academic libraries, including among other technology-related projects, the ability to share digitized resources via the World Wide Web; to ensure equity of access; and to help bring resources to underserved audiences. LSTA funds are distributed by the federal Institute of Museum and Library Services (IMLS) to the state agency responsible for libraries and library services in each of the fifty states. In North Carolina, the State Library of North Carolina receives LSTA funds and redistributes them through a variety of grant programs to individual libraries, library systems, and consortia to implement local and statewide library programs and projects.

I recently asked Penny Hornsby, Consultant for Federal Programs at the State Library of North Carolina, for LSTA figures for North Carolina as a percentage of total funds available nationally. For fiscal year 2003, for example, the total LSTA appropriation for the nation was $\$ 187,868,160$. Of this sum, $\$ 150,435,000$, or $80.07 \%$ was earmarked for state library programs. The difference in the two figures, $\$ 3,743,3160$, or $19.93 \%$, represents funding for Native American Grants, National Leadership Grants, and IMLS Administration. North Carolina's share of the 2003 LSTA funds for state library programs was $\$ 4,104,012$, which represents $2.18 \%$ of total LSTA program funds and $2.73 \%$ of LSTA funds earmarked for state library programs.

All of this sounds very impressive, at least it did to me, until recent reports were released that the U.S. government is spending one billion (that's nine zeros) dollars to fund a week of nation-rebuilding in Iraq. While $\$ 1$ billion is being spent internationally for activities in Iraq that will have no direct benefit domestically, libraries throughout the United States in one fiscal year will receive approximately 15 percent of $\$ 1$ billion, or $\$ 150.5$ million for LSTA state program funding. This amount is to provide library service to approximately 285 million Americans, based on a 2001 estimate, many of whom are still without adequate library service, including immigrants, African Americans, and Native Americans. Of 285 million Americans, approximately 8 million are North Carolinians.

Are libraries getting their fair share of federal funds? Are library services adequate in your community? Are all segments of the population receiving equal access to libraries? These questions are definitely interrelated. 